\title{
Investigation of methanol electro-oxidation on graphene supported platinum-tungsten catalyst
}

Teofilius Kilmonis*,

Antanas Nacys,

Dijana Šimkūnaitè,

Loreta Tamašauskaitė-Tamašiūnaitė ${ }^{*}$,

Aldona Balčiūnaitè,

Eugenijus Norkus

Department of Catalysis,

Center for Physical Sciences and Technology,

3 Sauletekio Avenue,

Vilnius 10257, Lithuania
The graphene (GR) supported platinum-tungsten (PtW) catalysts with Pt:W molar ratios, equal to 1.6:1, 2.3:1 and 7.1:1, were prepared by a rapid microwave-assisted heating method. The activity of the catalysts was investigated for the electro-oxidation of methanol in an alkaline medium by means of cyclic voltammetry (CV) and chronoamperometry (CA). It has been determined that the rate of methanol oxidation depends on the Pt:W molar ratio in the PtW/GR catalysts. From the CV measurements it follows that the highest current density values, specific and mass activities are obtained for the PtW/GR catalyst with the Pt:W molar ratio equal to 1.6:1. Similarly, the chronoamperometry measurements point to the best performance of the PtW/GR catalyst with the same Pt:W molar ratio. Moreover, in all cases the synthesized PtW/GR catalysts, regardless of different Pt:W molar ratio, show an enhanced electrocatalytic activity towards the direct electro-oxidation of methanol when compared with that for the bare Pt/GR and W/GR catalysts.

Keywords: platinum, tungsten, graphene, methanol, oxidation

\section{INTRODUCTION}

The increasing demand for fossil fuel alternatives inevitably forces scientists to search for other sustainable and energy-efficient sources. A sound solution to this problem is fuel cells (FCs) that are notified as next-generation power sources for their high energy densities and evident contribution to the strategies directed towards the implementation of innovative environment-friendly technologies [1]. Among different types of FCs developed so far direct methanol fuel cells (DMFCs) are considered as one of the most promising clean energy sources. They have been investigated extensively, especially for portable power supply [2, 3], and are receiving a significant attention due to a whole range of benefits including their superior specific energy, economical price and physi-

*Corresponding author. Email: teofilius.kilmonis@ftmc.lt; loreta.tamasauskaite@ftmc.lt cal state (a liquid form at ambient conditions) that unambiguously determine the operational safety of the system. Since the following cells use a liquid methanol solution as a fuel, conversely to those of hydrogen that deal with the gas as a fuel, DMFCs are considerably safer regarding the ease of fuel storage and transportation [4]. The main reactions occurring in the alkaline DMFCs are the oxidation of methanol at the anode (Eq. 1) and the reduction of oxygen at the cathode (Eq. 2) [5]:

Anode reaction:

$\mathrm{CH}_{3} \mathrm{OH}+6 \mathrm{OH}^{-} \rightarrow \mathrm{CO}_{2}+5 \mathrm{H}_{2} \mathrm{O}+6 \mathrm{e}^{-}$

Cathode reaction:

$3 / 2 \mathrm{O}_{2}+3 \mathrm{H}_{2} \mathrm{O}+6 \mathrm{e}^{-} \rightarrow 6 \mathrm{OH}^{-}$

Overall reaction: 


$$
\mathrm{CH}_{3} \mathrm{OH}+3 / 2 \mathrm{O}_{2} \rightarrow \mathrm{CO}_{2}+2 \mathrm{H}_{2} \mathrm{O} \text {. }
$$

However, a successful worldwide commercialization of DMFCs is largely related to the dependence on Pt or Pt-based electrocatalysts that are expensive and generate considerable manufacturing costs. One more drawback is a relatively low resistance of such catalysts towards carbon monoxide adsorption $\left(\mathrm{CO}_{\text {ads }}\right)$. Responding to these challenges a series of cost-effective and less susceptible towards $\mathrm{CO}_{\text {ads }}$ poisoning catalysts have been developed. Instead of the pure Pt bimetallic systems, containing the second less expensive metal, and thus the lower Pt loading, such as Pt$\mathrm{Ru}$ [6-11], Pt-Au [12, 13] and Pt-Pd [14-16], have been developed. Similarly, Pt alloying with non-noble (transition) metals, such as Co [17, 18], $\mathrm{Ni}[17], \mathrm{Cu}$ [17], Fe [19], $\mathrm{Mn}$ [20], Sn [20, 21], Zn [20], etc., facilitated further creating of cheaper catalysts. Multi-component systems, such as PtRuCuW [22], FePtSn [23] and FePtCu [24], have emerged and assisted in resolving the necessary major key challenges. It should be noted that generally the above-mentioned catalysts not only reduce the Pt loading and, therefore, lower the price of the catalysts, but also demonstrate an enhanced stability, a higher resistance to catalyst poisoning, and markedly improve the catalytic activity for the methanol oxidation reaction as compared to those characteristics of monometallic catalysts.

The selection of a suitable support material in catalyst development plays an essential role on the performance of the catalyst. The synergetic effect between the metal and the support results in an enhanced catalytic performance and a long-term durability [15]. Among the investigated catalysts tungsten (W) based catalysts have the potential to oxidize methanol either as the catalysts or the catalyst supports [25, 31]. They have been extensively studied for promoting the electrocatalytic activity of Pt [27, 8, 28, 29, 30]. High electrocatalytic activities and good stabilities are attributed to a synergistic effect between $\mathrm{Pt}$ and $\mathrm{W}$-based elements that avoid poisoning of the electrodes [27-32]. At the same time the presence of highly dispersed $\mathrm{W}$ particles in the catalyst system facilitates a better distribution of the whole catalyst on the support $[8,27,28]$. However, generally the Pt:W ratio is not controlled and tungsten oxide normally exists in excess. For that reason, the effects of the Pt:W ratio, size and structure on the electrocatalytic activity of the catalyst cannot be clarified. At present a very few studies on the control of the Pt:W ratio at the nanoparticle level have been reported [32, 33]. Moreover, almost no works, except [34], are devoted to the investigation of methanol oxidation in an alkaline medium onto the $\mathrm{Pt}-\mathrm{W}$-based catalyst, despite the fact that methanol oxidation kinetics is more facile in an alkaline medium than in an acidic one [35].

In our previous work [33] we have demonstrated that the GR supported Pt-W catalysts with different Pt:W molar ratios, equal to 1.6:1, 2.3:1 and 7.1:1, showed a considerably improved catalytic activity for the oxidation of sodium borohydride in an alkaline medium. We decided to apply the both mentioned catalysts for the electro-oxidation of methanol in an alkaline medium. GR was used as a support material in order to achieve a high dispersion of both the Pt and $\mathrm{W}$ nanoparticles. It is appreciated for its unique inherent characteristics like an extended surface area, a high catalyst loading, a good electrocatalysis and stability. [36]. The synthesis of the GR supported $\mathrm{Pt}-\mathrm{W}$ nanoparticles was performed by a microwave-assisted heating method, which allows one to control the Pt:W molar ratio in the resulting catalysts. The activity of the catalysts was tested for the electro-oxidation of methanol in an alkaline medium by means of cyclic voltammetry (CV) and chronoamperometry.

\section{EXPERIMENTAL}

\section{Chemicals}

$\mathrm{H}_{2} \mathrm{PtCl}_{6}$ (Sigma-Aldrich), $\mathrm{Na}_{2} \mathrm{WO}_{4} \cdot 2 \mathrm{H}_{2} \mathrm{O}$ (SigmaAldrich), ethylene glycol (EG) (Chempur), citric acid (Sigma-Aldrich), graphene powder (purity of $97 \%$, specific surface area $60 \mathrm{~m}^{2} / \mathrm{g}$, Graphene-Supermarket), Nafion (5 wt.\%, D521, 1100 EW, Ion Power Inc.) were used. All chemicals were of analytical grade and used without further purification. Ultra-pure water with a resistivity of $18.2 \mathrm{M} \Omega \mathrm{cm}^{-1}$ was used to prepare all the solutions.

\section{Fabrication of catalysts}

The graphene supported PtW catalysts with different Pt:W molar ratios were prepared by means of microwave heating of $\mathrm{H}_{2} \mathrm{PtCl}_{6}$ and $\mathrm{Na}_{2} \mathrm{WO}_{4} \cdot 2 \mathrm{H}_{2} \mathrm{O}$ 
in an EG solution according to the procedure described in detail earlier in Ref. [33]. Briefly, $0.25 \mathrm{ml}$ of $0.0974 \mathrm{M} \mathrm{H}_{2} \mathrm{PtCl}_{6}$, required amounts of $\mathrm{Na}_{2} \mathrm{WO}_{4} \cdot 2 \mathrm{H}_{2} \mathrm{O}$ (dissolved in a minimal amount of a $10 \mathrm{mM}$ citric acid solution) and $0.3 \mathrm{~g}$ graphene powder were mixed with $18.5 \mathrm{ml}$ of EG and sonicated for $30 \mathrm{~min}$. The synthesis was carried out in a microwave reactor Monowave 300 (Anton Paar) at $150^{\circ} \mathrm{C}$ temperature for $5 \mathrm{~min}$. For comparison, the bare Pt/GR and W/GR were prepared in the same manner. After the preparation, the synthesized catalysts were washed with acetone and ultra-pure water, then filtered and dried in a vacuum oven at $80^{\circ} \mathrm{C}$ temperature for $2 \mathrm{~h}$.

\section{Electrochemical measurements}

Methanol oxidation measurements were performed in the same manner as described in Ref. [33] using a Metrohm Autolab potentiostat PGSTAT100 and a three-electrode cell. The working electrode was a glassy carbon electrode with a geometric area of $0.07 \mathrm{~cm}^{2}$, which was coated with a thin layer of a Nafion-impregnated catalyst cast. The Pt sheet was used as a counter electrode and $\mathrm{Ag} / \mathrm{AgCl}$ as a reference electrode. The catalyst layer was obtained by mixing the required amounts of PtW/GR, W/GR or Pt/GR catalysts ultrasonically for $30 \mathrm{~min}$ in a solution containing $0.25 \mu \mathrm{l}$ of Nafion and $0.75 \mu \mathrm{l}$ deionized $\mathrm{H}_{2} \mathrm{O}$ to produce a homogenous slurry. Then, $5 \mu \mathrm{l}$ of the prepared suspension mixture was pipetted onto the polished surface of a glassy carbon electrode and dried in air for $12 \mathrm{~h}$. The electrocatalytic activity of catalysts towards methanol oxidation was carried out by recording cyclic voltammograms (CVs) in a $1 \mathrm{M} \mathrm{CH}_{3} \mathrm{OH}+1 \mathrm{M} \mathrm{NaOH}$ solution at a scan rate of $50 \mathrm{mV} \mathrm{s}^{-1}$ from $-0.7 \mathrm{~V}$ to $0.5 \mathrm{~V}$ at $25^{\circ} \mathrm{C}$ temperature. The chronoamperometric curves for the investigated $\mathrm{Pt} / \mathrm{GR}, \mathrm{W} / \mathrm{GR}$ and $\mathrm{PtW} / \mathrm{GR}$ catalysts were recorded at a constant potential value of $0.2 \mathrm{~V}$ for $30 \mathrm{~min}$. The presented current densities were normalized with respect to the geometric area of catalysts.

All solutions were deaerated by argon for 15 min prior to measurements.

\section{RESULTS AND DISCUSSION}

The graphene supported PtW catalysts with different Pt:W molar ratio were prepared by the means of a rapid microwave heating technique in the same manner as described in Ref. [33]. The Pt:W molar ratio in the synthesized catalysts equaled to 1.6:1, 2.3:1 and 7.1:1 The catalysts were denoted as PtW(1.6:1)/GR, PtW(2.3:1)/GR and PtW(7.1:1)/ GR), respectively. The Pt loadings for the abovementioned catalysts were determined by ICP-OES analysis: $73 \mu \mathrm{g}_{\mathrm{Pt}} \mathrm{cm}^{-2}$ for Pt/GR, $24.7 \mu \mathrm{g}_{\mathrm{Pt}} \mathrm{cm}^{-2}$ for $\mathrm{PtW}(1.6: 1) / \mathrm{GR}, 54.6 \mu \mathrm{g}_{\mathrm{Pt}} \mathrm{cm}^{-2}$ for PtW(2.3:1)/ GR and $41.4 \mu \mathrm{g} \mathrm{Pt} \mathrm{cm}^{-2}$ for PtW(7.1:1)/GR catalyst. Meanwhile, the loading of $\mathrm{W}$ in the pure W/GR catalyst equals to $4.1 \mu \mathrm{g}_{\mathrm{W}} \mathrm{cm}^{-2}$, while in PtW(1.6:1)/GR, PtW(2.3:1)/GR and PtW(7.1:1)/ GR it equals $14.4,21.9$ and $5.5 \mu \mathrm{g}_{\mathrm{W}} \mathrm{cm}^{-2}$, respectively. As was shown in Ref. [33], the average size of uniformly and well dispersed Pt nanoparticles on the surfaces of graphene in the Pt/GR catalyst was ca. $3 \mathrm{~nm}$, while the Pt nanoparticles in the PtW/ GR catalysts with different Pt loadings were found to be of ca. 5-20 nm in size. Moreover, the electrochemically active surface areas (ESAs) of Pt in the synthesized catalysts were found to be $2.3,3.2$, 3.6 and $5.2 \mathrm{~cm}^{2}$ for PtW(1.6:1)/GR, PtW(2.3:1)/ GR, PtW(7.1:1)/GR and Pt/GR catalysts, respectively [33]. The data analysis clearly pointed to the fact that ESA values for the PtW(1.6:1)/GR, $\mathrm{PtW}(2.3: 1) / \mathrm{GR}$ and PtW(7.1:1)/GR catalysts were ca. 2.3, 1.6 and 1.4 times lower compared to that obtained at the Pt/GR catalyst [33].

The electrochemical properties of the GR supported PtW catalysts having different Pt:W molar ratios were investigated with respect to the oxidation of methanol in an alkaline media by means of cyclic voltammetry. Figure 1 shows CVs for the W/GR (a), Pt/GR (b) and PtW/GR catalysts with Pt:W molar ratios equal to $1.6: 1$ (c), 2.3:1 (d), and 7.1:1 (e) recorded in $1 \mathrm{M} \mathrm{CH}_{3} \mathrm{OH}+1 \mathrm{M}$ $\mathrm{NaOH}$ at a scan rate of $50 \mathrm{mV} \mathrm{s}^{-1}$. For the sake of simplicity, in Fig. If only positive potentialgoing scans of stabilized CVs of all the catalysts are presented. As evident from the obtained data in Fig. 1, all CV plots exhibit two typical anodic peaks in the forward and reverse scans (labelled as I and II), which are well-known to reflect the electrooxidation of alcohols and the intermediate carbonaceous species, respectively [37]. The first anodic current peak $\mathbf{I}$ in the forward scan is related to the oxidation of methanol on the catalyst, whereas the second anodic peak II on the reverse scan may be related to the oxidation of 


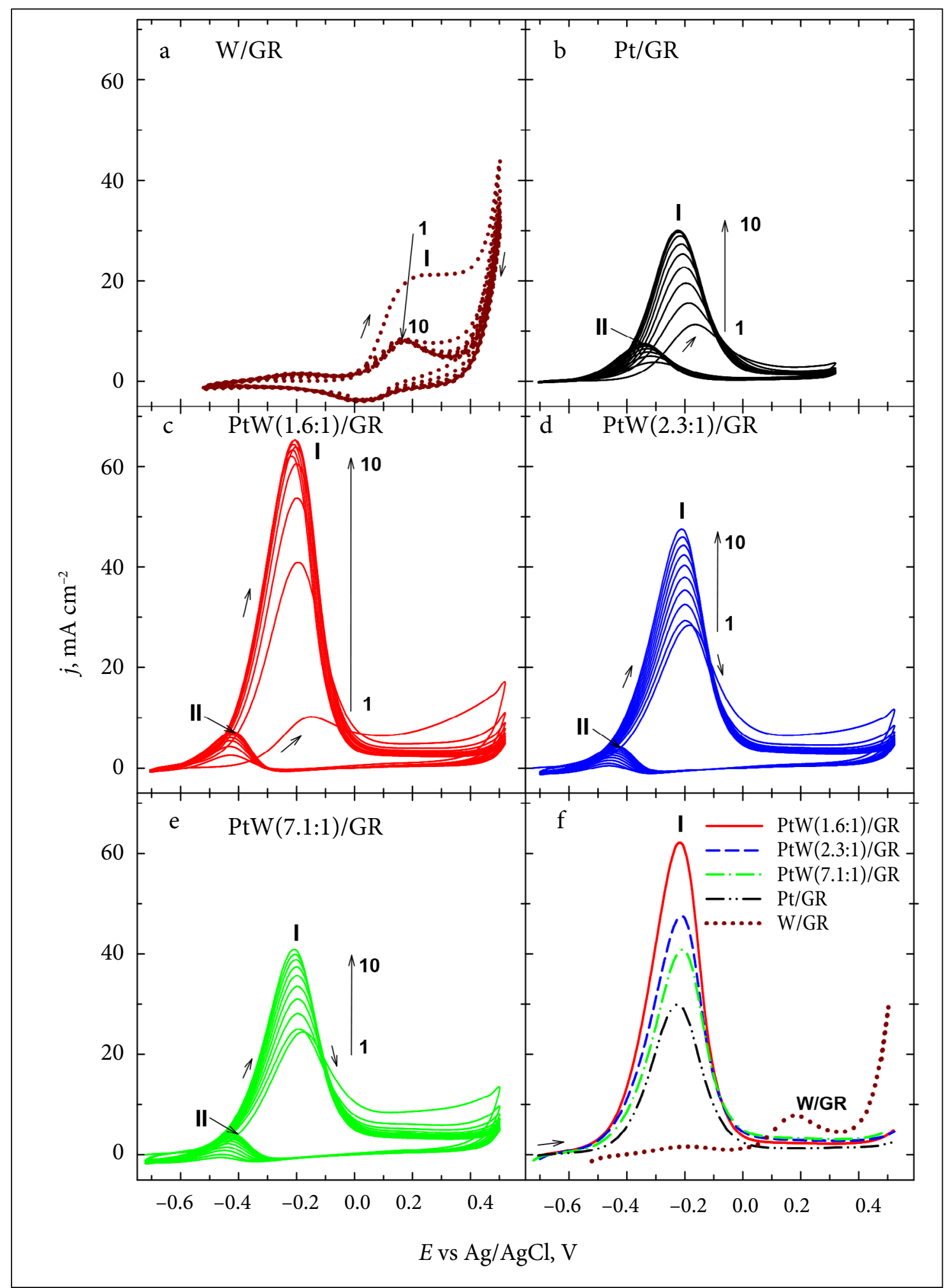

Fig. 1. CVs recorded at W/GR (a), Pt/GR (b), PtW(1.6:1)/GR (c), PtW(2.3:1)/GR (d), PtW(7.1:1)/GR (e) and stabilized positive potential-going scans for the same catalysts in $1 \mathrm{M} \mathrm{CH}, \mathrm{OH}+1 \mathrm{M} \mathrm{NaOH}$ at $50 \mathrm{mV} \mathrm{s}^{-1}$

intermediate products generated during the forward scan [37].

During the long-term cycling, the current density values on the W/GR catalyst (Fig. 1a) significantly decrease, immediately after the first po- tential scan, to a rather low current value of ca. $7.8 \mathrm{~mA} \mathrm{~cm}^{-2}$. Meanwhile, the methanol oxidation current values recorded on the Pt/GR (Fig. $1 \mathrm{~b}$ ) or PtW/GR (Fig. 1 $1 \mathrm{c}-\mathrm{e}$ ) catalysts increase with the scan number and depend on the Pt:W molar ratio in 
the catalyst. Moreover, the onset potential of methanol oxidation at the W/GR catalyst is obtained in a rather positive potential region at a potential value of ca. $0.057 \mathrm{~V}$ that is almost ca. $0.5 \mathrm{~V}$ more positive than those observed for $\mathrm{Pt} / \mathrm{GR}$ or $\mathrm{PtW} / \mathrm{GR}$ (ca. $-0.45 \mathrm{~V}$ ) (Fig. 1f). A lower onset potential suggests that the overpotential of methanol oxidation is lower and the electrocatalytic methanol oxidation occurs more easily on Pt/GR or PtW/GR. Therefore, the $\mathrm{Pt} / \mathrm{GR}$ or PtW/GR catalysts with different Pt:W molar ratios are considered to be of a higher activity towards methanol oxidation compared to that of $\mathrm{W} / \mathrm{GR}$.

The stabilized CVs of the investigated catalysts presented in Fig. If show that the highest current density is obtained at the PtW/GR catalyst with the lowest Pt loading of $24.7 \mu \mathrm{g} \mathrm{Pt} \mathrm{cm}{ }^{-2}$ and containing the Pt:W molar ratio equal to 1.6:1. The current densities of peak I recorded on the PtW(1.6:1)/ GR, PtW(2.3:1)/GR and PtW(7.1:1)/GR catalysts are ca. 2.1, 1.6 and 1.4 times higher than those on Pt/GR and, considerably more, i.e. ca. 7.8, 6.0 and 5.2 times higher compared to those obtained on the W/GR catalyst. The enhanced electrocatalytic activity of the synthesized PtW/GR catalysts may be attributed to the Pt electronic structure change due to the presence of $\mathrm{W}[8,27,28]$.

In addition, it is well known that the ratio of forward anodic peak current $\left(j_{\mathrm{F}}\right)$ to the backward anodic peak $\left(j_{\mathrm{B}}\right), j_{\mathrm{F}} / j_{\mathrm{B}}$, is an index of the catalysts tolerance to the poisoning species accumulated on the surface of the electrode $[38,39]$. The ratios $j_{\mathrm{F}} /$ $j_{\mathrm{B}}$ were 8.7, 10.9, 9.8 and 4.1 for the $\mathrm{PtW}(1.6: 1) /$ GR, PtW(2.3:1)/GR, PtW(7.1:1)/GR and Pt/GR catalysts, respectively. A higher $j_{\mathrm{F}} / j_{\mathrm{B}}$ ratio indicates an efficient oxidation of methanol during the forward scan, with a little accumulation of carbonaceous residues [38, 39]. Notably, the ratio $j_{\mathrm{F}} / j_{\mathrm{B}}$ was ca. 2 times higher for the all PtW/GR catalysts as compared with that for the pure Pt/GR catalysts, indicating a greater efficiency of the PtW/GR catalysts towards the electro-oxidation of methanol in an alkaline medium.

In order to evaluate the electrocatalytic activity of the catalysts, the methanol oxidation current density values under the potential region of peak I were normalized by the electrochemically active surface areas and the Pt loadings for each catalyst to represent the specific and mass activity of the catalysts. Figure 2 presents the calcu-

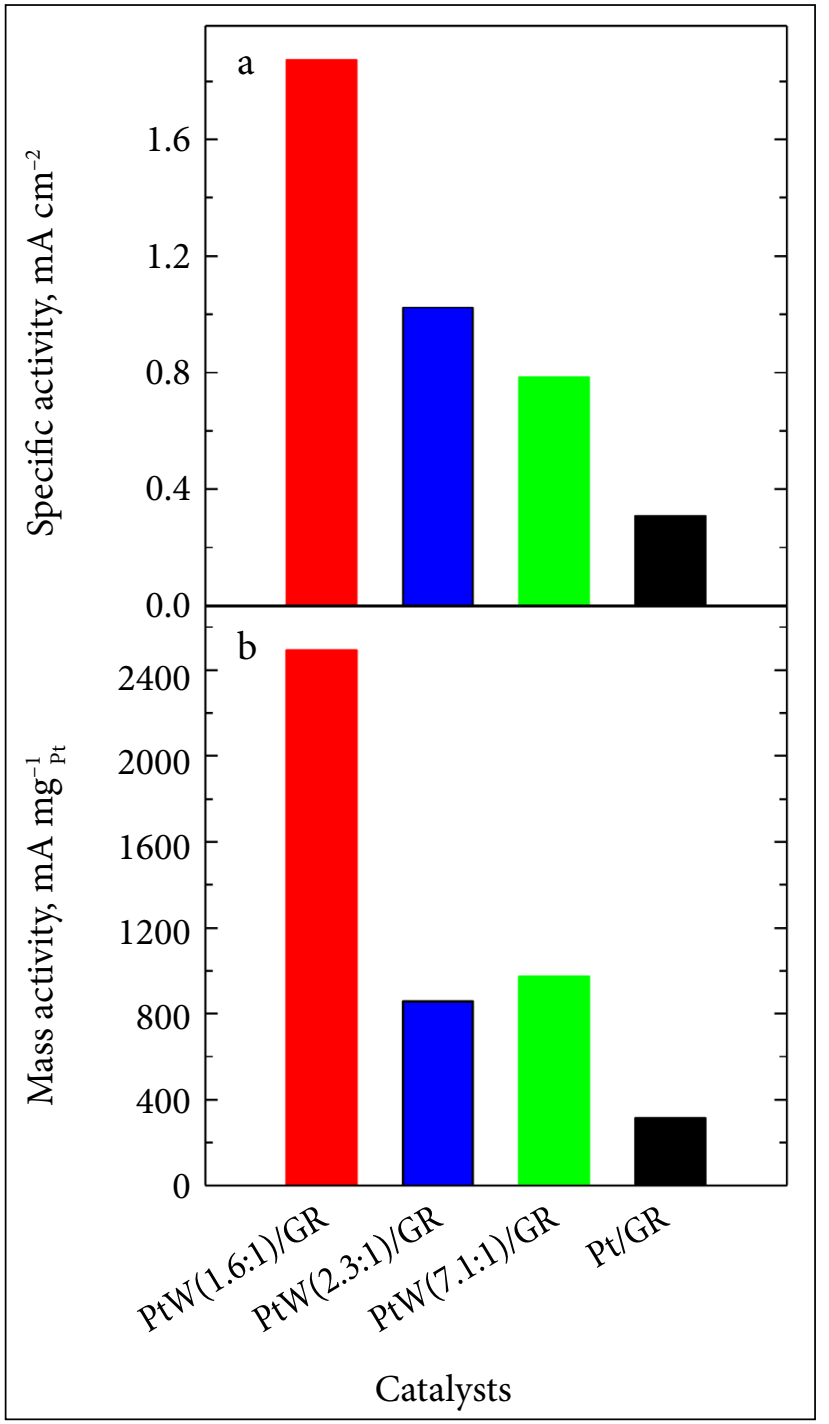

Fig. 2. Current densities normalized by ESA (a) and Pt loadings (b) for Pt/GR, PtW(1.6:1)/GR, PtW(2.3:1)/GR and PtW(7:1)/GR catalysts in $1 \mathrm{MCH}_{3} \mathrm{OH}+1 \mathrm{M} \mathrm{NaOH}$ at $50 \mathrm{mV} \mathrm{s}^{-1}$

lated specific (a) and mass (b) activity values of the prepared catalysts. As seen from the data in Fig. 2, all the PtW/GR catalysts with different Pt:W molar ratios outperformed the bare Pt/GR catalyst in respect to both specific activity and mass activity. Assuming ca. 2.3, 1.6 and 1.4 times higher active surface area of the Pt/GR catalyst compared to those of the PtW(1.6:1)/GR, PtW(2.3:1)/GR and $\mathrm{PtW}(7.1: 1) / \mathrm{GR}$ catalysts, respectively, the surface area normalized methanol oxidation current densities under peak I, on the contrary, are ca. 4.6, 2.6 and 2.0 times higher on the latter catalysts (Fig. 2a). Similarly, the mass activities of the same PtW(1.6:1)/GR, PtW(2.3:1)/GR and PtW(7.1:1)/ GR catalysts are ca. 6.1, 2.1 and 2.4 times higher than that at Pt/GR (Fig. 2b). 
The catalytic stability of the synthesized catalysts for the oxidation of methanol was further investigated under chronoamperometric conditions. Figure 3 presents the chronoamperometric curves obtained at the $\mathrm{Pt} / \mathrm{GR}, \mathrm{W} / \mathrm{GR}$ and $\mathrm{PtW} / \mathrm{GR}$ catalysts in a $1 \mathrm{M} \mathrm{CH}_{3} \mathrm{OH}+1 \mathrm{M} \mathrm{NaOH}$ solution at a fixed potential value of $-0.2 \mathrm{~V}$ for $1800 \mathrm{~s}$. All the catalysts show a current decay for the methanol oxidation reaction. Such behaviour might be explained by the formation of intermediate species, such as $\mathrm{CO}_{\text {ads }}, \mathrm{CHO}_{2 \mathrm{ds}}$, etc., during the methanol oxidation reaction [40]. The current densities obtained at a fixed potential value of $-0.2 \mathrm{~V}$ for all synthesized PtW/GR catalysts are higher than those for the bare $\mathrm{Pt} / \mathrm{GR}$ and W/GR. After exposing the catalysts at the mentioned potential for a time period equal to $1800 \mathrm{~s}$, the current density values of methanol oxidation at the PtW/GR catalysts with Pt:W molar ratios of 1.6:1, 2.3:1 and 7.1:1 were found to be ca. 2.0, 2.4 and 1.3 times, respectively, higher than those at Pt/GR. This indicates a higher electrocatalytic activity and stability of the prepared PtW/GR catalysts towards the oxidation of methanol (Fig. 3). The normalized methanol oxidation current densities by ESA values and Pt loadings for each catalyst obtained under chronoamperometric conditions are shown in Fig. 4. Similarly, the specific activity

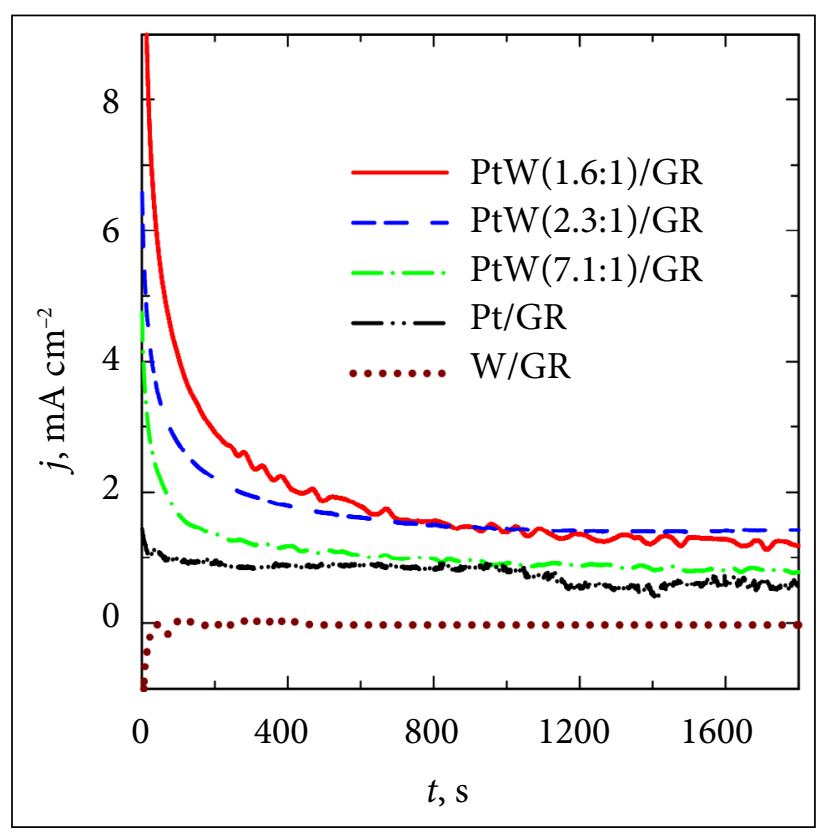

Fig. 3. Chronoamperometric data recorded for W/GR (dotted line), $\mathrm{Pt} / \mathrm{GR}$ (dash-dot-dotted line), PtW(1.6:1)/GR (solid line), PtW(2.3:1)/ GR (dashed line), and PtW(7:1)/GR (dash-dotted line) catalysts in $1 \mathrm{M}$ $\mathrm{CH}_{3} \mathrm{OH}+1 \mathrm{M} \mathrm{NaOH}$ at $\mathrm{E}=-0.2 \mathrm{~V}$ for $1800 \mathrm{~s}$

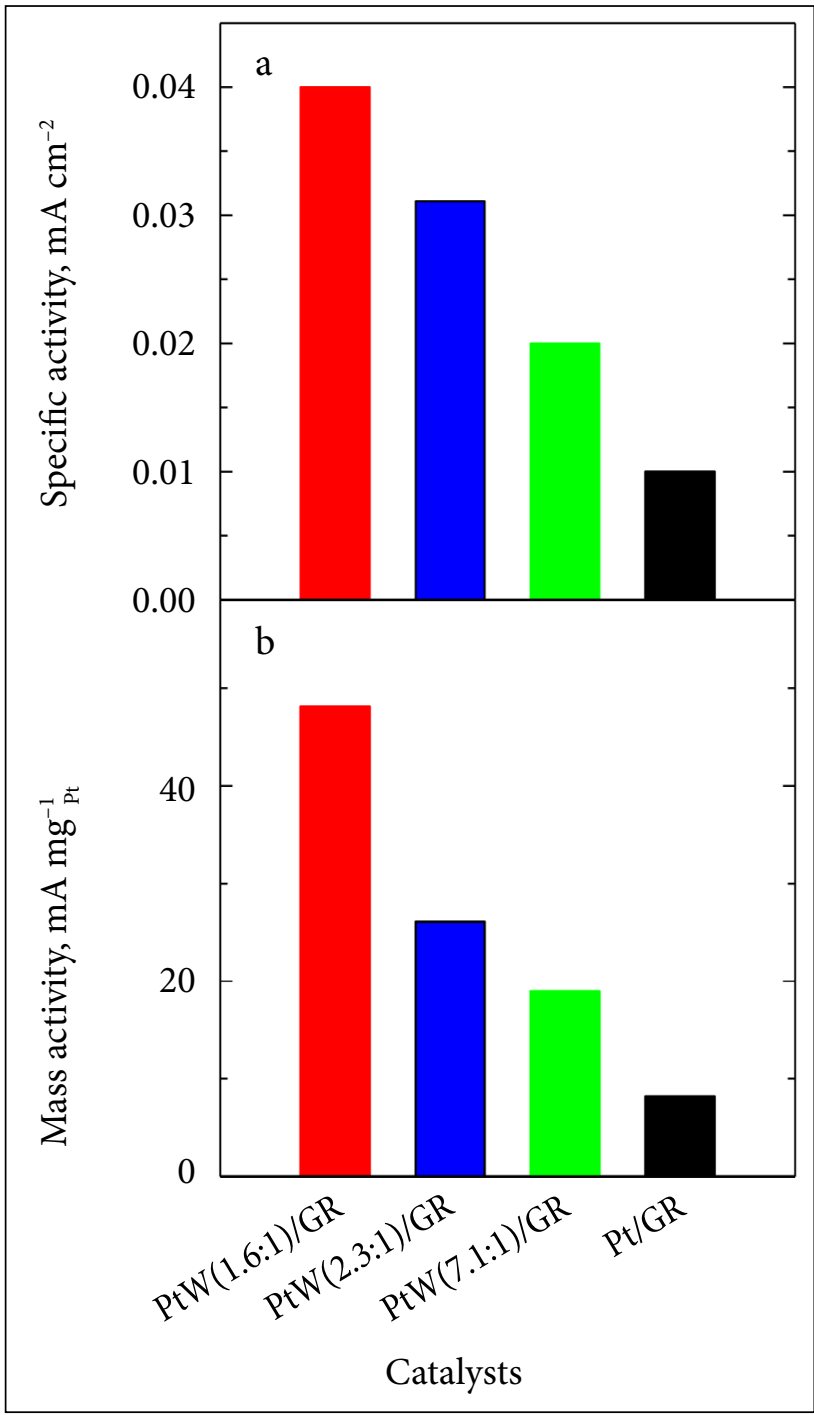

Fig. 4. Comparison of specific (a) and mass (c) activities for the same catalysts as in Fig. 3

values calculated for the PtW/GR catalysts ca. 2.04.6 times outperform the ones for Pt/GR, whereas ca. 2.1-6.1 times higher mass activity values were obtained on the PtW/GR catalysts as compared with those at the Pt/GR catalyst. Notably, both specific and mass activities depend on the Pt:W molar ratio in the catalyst. The highest normalized current density values at a potential value of $-0.2 \mathrm{~V}$ are obtained at the PtW/GR catalyst with the Pt:W molar ratio equal to 1.6:1. It shows ca. 4.5 and 5.9 times higher specific and mass activities, respectively, compared with those for the Pt/GR catalyst. The obtained results well coincide with those parameters found by cyclic voltammetry measurements that are 4.6 and 6.1, respectively.

The voltammetric and chronoamperometric measurements confirm that the $\mathrm{PtW}(1.6: 1) / \mathrm{GR}$, 
PtW(2.3:1)/GR and PtW(7.1:1) catalysts, which were prepared via a simple and rapid microwave heating method, exhibit a higher electrocatalytic activity and a better stability towards the oxidation of methanol in an alkaline medium than that of $\mathrm{Pt} /$ GR and W/GR catalysts.

\section{CONCLUSIONS}

A simple and rapid microwave heating method was applied to prepare the graphene supported $\mathrm{PtW}$ catalysts having Pt:W molar ratios equal to 1.6:1, 2.3:1 and 7.1:1. It has been determined that the rate of methanol oxidation in an alkaline media depends on the Pt:W molar ratio in the PtW/ GR catalysts, which greatly influences the activity for the oxidation of methanol. The highest current density values, specific and mass activities have been obtained for the PtW/GR catalyst with the lowest Pt loading of $24.7 \mu \mathrm{g}_{\mathrm{Pt}} \mathrm{cm}^{-2}$, corresponding to the Pt:W molar ratio equal to $1.6: 1$. Moreover, in all cases the prepared PtW/GR catalysts, regardless of different $\mathrm{Pt}: \mathrm{W}$ molar ratios, show an enhanced electrocatalytic activity towards the direct oxidation of methanol compared with that for the bare Pt/GR and W/GR catalysts. The specific and mass activity values calculated for the PtW/ GR catalysts with different Pt:W molar ratios by a voltammetric method outperform ca. 2.0-4.6 and ca. 2.1-6.1 times, respectively, as compared with those calculated for the Pt/GR catalyst, and well coincide with the same parameters calculated by chronoamperometric measurements, that are ca. 1.9-4.5 or ca. 2.3-5.9 times higher, respectively, than those calculated for the Pt/GR catalyst.

The graphene supported PtW catalysts synthesized by means of microwave-assisted heating seem to be a promising anode material for direct methanol fuel cells.

Received 19 June 2019 Accepted 26 June 2019

\section{References}

1. B. C. H. Steele, A. Heinzel, Nature, 414, 345 (2001).

2. M. Goor, S. Menkin, E. Peled, Int. J. Hydrogen Energy, 44, 3138 (2019).

3. L. Yang, J. Ge, C. Liu, et al., Curr. Opin. Electrochem., 4, 83 (2017).

4. L. Gong, Z. Yang, K. Li, et al., J. Energy Chem., 27, 1618 (2018).
5. B. Wang, Y. Zhou, Q. Du, et al., Appl. Therm. Eng., 100, 1245 (2016).

6. M. L. Xiao, L. G. Feng, J. B. Zhu, et al., Nanoscale, 7(21), 9467 (2015).

7. S. Zhao, H. Yin, L. Du, et al., J. Mater. Chem., 2(11), 3719 (2014).

8. W. Chen, X. Wei, Y. Zhang, Int. J. Hydrogen Energy, 39, 6995 (2014).

9. F. Luo, Q. Zhang, K. Qu, et al., Chem. Cat. Chem., 11, 1 (2019).

10. M. Li, H. Zheng, G. Han, et al., Catal. Commun., 92, 95 (2017).

11. N. Kakati, S. H. Lee, J. Maiti, et al., Surf. Sci., 606(21-22), 1633 (2012).

12. G. Chang, Z. Cai, H. Jia, et al., Int. J. Hydrogen Energy, 43, 12803 (2018).

13. N. Prabu, D. Jeyakumar, ChemistrySelect, 3, 13207 (2018).

14. H. Wang, L. Sheng, X. Zhao, et al., Curr. Appl. Phys., 18, 898 (2018).

15. R. Arukula, M. Vinothkannan, A. R. Kim, et al., J. Alloys Compd., 771, 477 (2019).

16. M. F. R. Hanifah, J. Jaafar, M. H. D. Othman, et al., J. Alloys Compd., 793, 132 (2019).

17. F. Lei, Z. Li, L. Zhang, et al., J. Electrochem. Soc., 163(8), F913 (2016).

18. J. Zhao, Y. Zhou, L. Qin, Mater. Lett., 216, 166 (2018).

19. Q. Lv, Y. Xiao, M. Yin, et al., Electrochim. Acta, 139, 61 (2014).

20. K. M. El-Khatiba, R. M. A. Hameed, R. S. Amina, et al., Microchem. J., 145, 566 (2019).

21. M. S. C, Çögenli, A. B. Yurtcan, Int. J. Hydrogen Energy, 43, 10698 (2018).

22. X. Chen, H. Wang, Y. Wang, et al., Catalysts, 5(3), 1003 (2015).

23. Z. Wang, H. Fan, H. Liang, et al., Electrochim. Acta, 230, 245 (2017).

24. Y.-X. Wang, Ch.-F. Liu, M.-L. Yang, et al., Chin. Chem. Lett., 28, 60 (2017).

25. E. Antolini, E. R. Gonzalez, Appl. Catal., B, 96, 245 (2010).

26. J. Zeng, C. Francia, C. Gerbaldi, et al., Electrochim. Acta, 94, 80 (2014).

27. C. L. Lin, C. C. Wang, Appl. Energy, 164, 1043 (2016).

28. Z. Cui, L. Feng, C. Liu, et al., J. Power Sources, 196, 2621 (2011).

29. V. M. Nikolic, I. M. Perovic, N. M. Gavrilov, et al., Int. J. Hydrogen Energy, 39, 11175 (2014).

30. S. M. Brković, V. M. Nikolić, M. P. M. Kačinski, et al., Int. J. Hydrogen Energy, 44, 13364 (2019).

31. T. Maiyalagan, B. Viswanathan, J. Power Sources, 175, 789 (2008).

32. C. Yang, N. K. van der Laak, K.-Yu Chan, et al., Electrochim. Acta, 75, 262 (2012).

33. T. Kilmonis, L. Tamašauskaitè-Tamašiūnaitè, A. Balčiūnaitè, et al., Chemija, 27, 143 (2016). 
34. K. Mohammad, A. Forouzan, Z. H. R. L. Zadeh, et al., J. Fuel Chem. Technol., 41, 91 (2013).

35. A. V. Tripkovic, K. D. Popovic, B. N. Grgur, et al., Electrochim. Acta, 47, 3707 (2002).

36. N. Seselj, C. Engelbrekt, J. Zhang, Sci. Bull., 60(9), 864 (2015).

37. Y. Zhang, Y. Liu, W. Xiying, et al., Appl. Surf. Sci., 407, 64 (2017).

38. Y. Zhao, L. Zhan, J. Tian, et al., Electrochim. Acta, 56, 1967 (2011).

39. Y. H. Qin, H. H. Yang, X. S. Zhang, et al., Int. J. Hydrogen Energy, 35, 7667 (2010).

40. M. Jing, L. Jiang, B. Yi, et al., J. Electroanal. Chem., 688, 172 (2013).
Teofilius Kilmonis, Antanas Nacys, Dijana Šimkūnaitė, Loreta Tamašauskaitė-Tamašiūnaitė, Aldona Balčiūnaitė, Eugenijus Norkus

\section{METANOLIO ELEKTROOKSIDACIJOS ANT PLATINOS-VOLFRAMO / GRAFENO KATALIZATORIŲ TYRIMAS}

Santrauka

Platinos-volframo katalizatoriai buvo formuojami ant grafeno (GR) pagrindo (PtW/GR) taikant mikrobangų sintezę. Susintetinti PtW/GR katalizatoriai, kuriuose $\mathrm{Pt}: \mathrm{W}$ molinis santykis buvo $1,6: 1 ; 2,4: 1$ ir 7,1:1. Šu katalizatorių elektrokatalizinis aktyvumas metanolio oksidacijos reakcijai šarminëje terpèje buvo tiriamas naudojant ciklinę voltamperometriją ir chronoamperometriją.

Nustatyta, kad PtW/GR katalizatoriai pasižymi didesniu elektrokataliziniu aktyvumu metanolio oksidacijai, palyginti su grynais Pt/GR ar W/GR katalizatoriais, ir priklauso nuo $\mathrm{Pt}: \mathrm{W}$ molinio santykio. Visu tirtų PtW/GR katalizatorių tiek specifinio, tiek masès aktyvumo vertès, ivertintos taikant voltamperometrijos ir chronoamperometrijos tyrimo metodus, sutampa nepriklausomai nuo Pt:W molinio santykio, yra žymiai aukštesnès, palyginti su vertėmis, paskaičiuotomis Pt/GR ar W/GR katalizatoriams. 